\title{
0 reconhecimento do guia de turismo e as pesquisas sobre essa atividade profissional nas revistas científicas brasileiras $^{1}$
}

\author{
Bianca Paes Garcia dos Santos \\ Edegar Luís Tomazzoni ${ }^{b}$
}

\begin{abstract}
Resumo
O guia de turismo é o profissional que atua para proporcionar, ao turista, experiências de qualidade em suas viagens, além de contribuir para a preservação da identidade e dos valores do destino. 0 objetivo deste artigo é investigar as publicações sobre guias de turismo nas revistas acadêmicas brasileiras da área. Verificam-se os enfoques dos artigos e a relação entre o reconhecimento da atividade e a presença do tema nas publicações. Por meio da revisão sistemática da literatura, identificaram-se 22 publicações sobre a atividade profissional, em revistas científicas nacionais. As análises mostram uma recente rede dos autores que publicaram sobre a temática. Nota-se que a primeira publicação sobre o assunto é datada de 1999, embora, a regulamentação da profissão tenha sido em 1993. Elaborou-se uma nuvem com as palavras-chave, utilizadas nos artigos, considerando os autores e as referências. Constatou-se a existência de obras fundamentais para as pesquisas sobre a temática e de enfoque das pesquisas. Apesar da relevância da profissão, verificou-se que as publicações sobre a temática são recentes, e o grupo de pesquisadores é restrito, o que representa possibilidades significativas de produção científica na área.
\end{abstract}

Palavras-chave: Guia de turismo; Serviço de guia; Pesquisa; Brasil.

\begin{abstract}
The recognition of the tour guide and the research on this professional activity in Brazilian scientific journals

ed The tour guide is the professional who works to provide qualified experiences to the tourists on their travels, in addition to contributing to the preservation of the destination's identity and values. The purpose of this article is to investigate publications on tourism guides in the Brazilian academic journals. The focus of the articles and the relationship between the recognition of the activity and the presence of the theme in the publications are verified. Through literature research, 22 publications on the professional activity were identified in national scientific journals. The analyzes show a recent network of authors who published on the theme. It is noted that the first publication on the subject is dated 1999, although the profession was regulated in 1993. A cloud was created with the keywords used in the articles, considering the authors and the references. It was
\end{abstract}

a. Mestranda em Turismo pelo Programa de Pós-graduação da Escola de Artes, Ciências e Humanidades da Universidade de São Paulo (EACH-USP), São Paulo, São Paulo, Brasil. E-mail: biancapgsantos@ usp.br

b. Doutor em Ciências da Comunicação pelo Programa de Pós-Graduação da Escola de Comunicações e Artes da Universidade de São Paulo (ECA-USP). Docente do Programa de Pós-Graduação em Turismo e do Curso de Lazer e Turismo na Escola de Artes, Ciências e Humanidades da Universidade de São Paulo (EACH-USP), São Paulo, São Paulo, Brasil. E-mail: eltomazzoni@usp.br 
found the existence of fundamental works for research on the theme and research focus. Despite the relevance of the profession, it was found that publications on the subject are recent, and the group of researchers is restricted, which represents significant possibilities for scientific production in the area.

Keywords: Tour guide; Tour guide service; Research; Brazil.

\section{Resumen \\ El reconocimiento del guía turístico y la investigación sobre esta actividad profesional en las revistas científicas brasileñasl}

El guía turístico es el profesional que trabaja para brindar a los turistas experiencias de calidad en sus viajes, además de contribuir a la preservación de la identidad y los valores del destino. El propósito de este artículo es investigar publicaciones sobre guías de turismo en revistas académicas brasileñas en el área. Se verifica el enfoque de los artículos y la relación entre el reconocimiento de la actividad y la presencia del tema en las publicaciones. A través de la revisión de la literatura, se identificaron 22 publicaciones sobre actividad profesional en revistas científicas nacionales. Los análisis muestran una red reciente de autores que publicaron sobre el tema. Cabe señalar que la primera publicación sobre el tema tiene fecha de 1999, aunque la profesión se reguló en 1993. Se creó una nube con las palabras clave utilizadas en los artículos, considerando los autores y las referencias. Se encontró la existencia de trabajos fundamentales para la investigación sobre el tema y el enfoque de investigación. A pesar de la relevancia de la profesión, se encontró que las publicaciones sobre el tema son recientes, y el grupo de investigadores está restringido, lo que representa posibilidades significativas para la producción científica en el área.

Palabras clave: Guía de turismo; Servicio de guia de turismo; Pesquisa; Brasil.

\section{INTRODUÇÃo}

Os guias de turismo são os profissionais que orientam, acompanham e transmitem informações aos turistas, repassam conhecimentos sobre a cultura local e sobre os atrativos a serem visitados, bem como as regras e as normas para visitação (Chimenti \& Tavares, 2007; İrígüler \& Güler, 2016; Rabotic, 2010; Valle, 2004). Guia de Turismo é a única profissão da área do turismo reconhecida e regulamentada, até o momento, no país (Brasil, 1993, 2014, 2020). Em razão disso, o guia de turismo é visto como profissional mediador entre o turista e a comunidade receptiva, uma vez que interage com diversos atores da oferta e da demanda serviços turísticas (Holloway, 1981; Rabotic, 2010).

A profissão do guia de turismo foi chamada de "Cinderella" do turismo por Mak, Wong e Chang (2011, p. 1442), por ser atraente e útil, mas, ainda assim, nem sempre reconhecida. 0 guia de turismo "possui a capacidade e a oportunidade de promover os recursos e as atrações turísticas da localidade" (Zettermann \& Vergara, 2017, p. 186), além das responsabilidades de garantir que os serviços contratados (transporte, hospedagem, restaurantes, entre outros) possam ser cumpridos e de lidar com situações não programadas (desentendimentos, doenças, acidentes, extravios de bagagens, perda de documentos) (Trigo, 2009).

Soma-se a isso a função de transmitir, aos turistas, conhecimentos sobre a cultura local e sobre os atrativos a serem visitados, bem como as regras e as normas 
para visitação, justamente por serem eles a linha de frente dos trabalhadores do turismo (Ap \& Wong, 2001; Rabotic, 2010; Valle, 2004). De acordo com Ap e Wong (2001), os guias de turismo têm a capacidade de transformar simples visitações turísticas em verdadeiros passeios de experiência.

Esse profissional atua para garantir ao turista as melhores experiências possíveis, momentos, impressões e lembranças, além de contribuir para a preservação da identidade e dos valores do destino turístico (Chimenti \& Tavares, 2007; İrígüler \& Güler, 2016; Holloway, 1981; Picazo, 1996; Rabotic, 2010; Valle, 2004). Sem essa mediação dos guias de turismo, segundo Rabotic (2010), muitos recursos dos destinos permaneceriam incompreendidos, indisponíveis ou não seriam valorizados pelos visitantes.

Holloway (1981) identificou, há quase 40 anos, que havia escassez de estudos sobre os guias de turismo e até o momento verifica-se dificuldade em encontrar publicações e pesquisas que tratem sobre a temática do guia de turismo, o que leva a crer que tal atividade profissional não é destacada nas investigações científicas.

Por esta razão, o objetivo geral deste estudo é investigar as publicações sobre guias de turismo nas revistas acadêmicas brasileiras de turismo. 0 objetivo específico é entender os enfoques dos artigos, conforme os períodos das publicações sobre o tema. 0 trabalho estrutura-se em uma revisão literária e estudos bibliométricos sobre os guias de turismo no Brasil. A seguir, são apresentados os métodos de pesquisa, os resultados e discussões e, por fim, as conclusões.

\section{REVISÃo DE LITERATURA}

Diferentemente de outros trabalhadores do turismo, os guias estabelecem uma relação muito próxima com os visitantes, por essa razão, conseguem proteger os interesses da localidade (İrígüler \& Güler, 2016; Rabotic, 2010). Podem atuar no turismo receptivo, recebendo turistas de outras localidades em um determinado destino, ou no turismo emissivo, levando turistas de diversas localidades a um determinado destino (Zettermann \& Vergara, 2017).

No Brasil, a profissão do guia de turismo é regulamentada pela lei no $\mathbf{0} .623$ de 1993. "O guia de turismo é o profissional que, devidamente cadastrado no Instituto Brasileiro de Turismo (EMBRATUR), exerça atividades de acompanhar, orientar e transmitir informações a pessoas ou grupos, em visitas, excursões urbanas, municipais, estaduais, interestaduais, internacionais ou especializadas" (Brasil, 1993).

Observam-se as competências da antiga EMBRATUR foram transferidas para o Ministério do Turismo com a Lei 10.683/03. Dessa forma, os guias de turismo devem possuir formação técnica específica e se cadastrarem no referido Ministério, via sistema online, CADASTUR - Sistema Nacional de Cadastro de Prestadores de Serviços. "Este trabalho é delegado aos órgãos de turismo das unidades federativas de todo o País. Também é obrigação do guia portar sempre o seu crachá de identificação, em local visível, no exercício da profissão" (Nascimento et al., 2014, p. 27). 
Segundo a plataforma Cadastur (2020), os guias de turismo são a segunda categoria com maior número de cadastros, atrás apenas das agências de viagens. Existem, no Brasil, (2020) 24.284 guias de turismo, distribuídos pelas 27 unidades da federação. As maiores concentrações estão nos estados: Rio de Janeiro, São Paulo, Paraná e Rio Grande do Sul. Dentre os estados com menores números, estão Rondônia, Roraima, Acre e Amapá.

Figura 1 - Distribuição dos guias de turismo por estado do Brasil

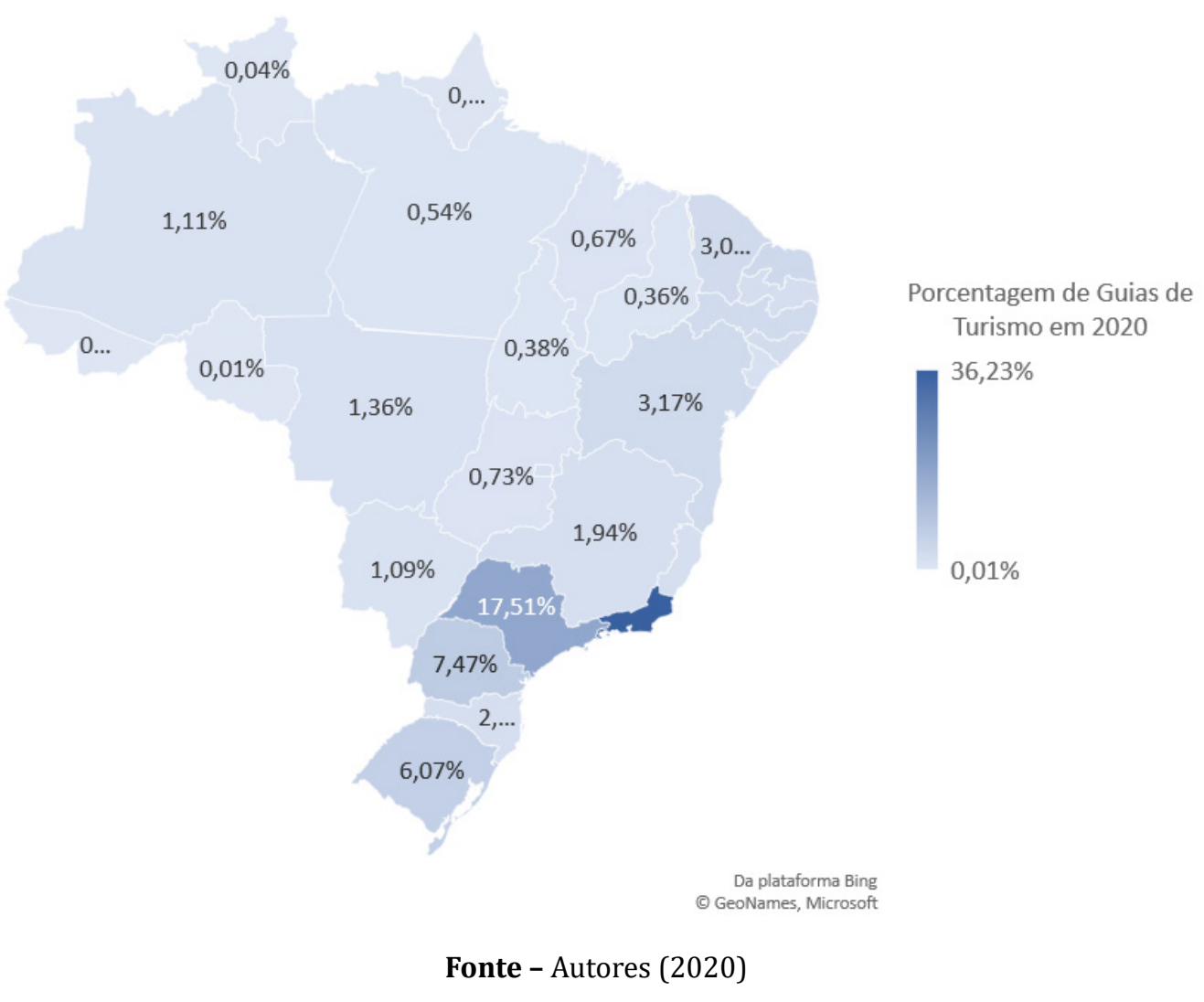

Internacionalmente, o tema também é discutido. Ap e Wong (2001) dizem que, em Hong Kong, existe um sistema de registro voluntário realizado por guias mais experientes, e que fornecem "estágios" aos novos guias, mas não há certificação ou licenciamento oficial, o que ocasiona níveis variáveis de profissionalismo. Chilembwe e Mweiwa (2014) recomendam, como solução para o caso do Malawi: a introdução de um treinamento formal, a instituição de uma associação representativa da classe e o registro e a certificação dos guias de turismo de forma oficial pelo governo local. Rabotic (2010) explica que a União Europeia, em 2008, apresentou um importante passo para o modo de treinamento profissional e os padrões necessários para a prática.

Uma das conquistas advindas da regulamentação foi a exigência de cadastramento junto ao agora Ministério e, além disso, a necessidade de um curso de formação específico. A formação de nível técnico, de acordo com o Ministério da Educação (MEC), deve ter, no mínimo, 800 horas (Cardoso \& Guzman, 2011; Nascimento et al., 2014) 
No Brasil, no que tange os aspectos legislativos sobre os guias de turismo, a primeira menção a esse profissional foi a Resolução Normativa CNTur no 04 de 1983 que subdividia os guias entre: guia local, guia de excursão e guia especializado. Essa normativa que reconhecia a profissão de guia foi extinta no início dos anos 1990, quando a CNTur também foi extinta, e a EMBRATUR tornouse Instituto (Zettermann \& Vergara, 2017).

Dez anos depois, a profissão foi regulamentada pela lei no 8.623 de 1993 e pelo decreto no 946 do mesmo ano. 0 decreto no 946 pontua os trâmites para tornar-se um guia de turismo - curso específico, cadastro - além das infrações e penalidades que pode sofrer com o não cumprimento da referida lei e do decreto. Esse decreto foi complementado em 2001, pela Deliberação Normativa no 427, no que diz respeito aos critérios de apreciação dos planos de curso para a educação profissional de nível técnico de guia de turismo (Brasil, 2001; Cardoso \& Guzman, 2011; Zettermann \& Vergara, 2017).

Até então, os guias de turismo eram pessoas físicas, que prestavam serviço para agências de viagens. Desde a portaria MTur no 130 de 2011, os guias de turismo passaram a poder se cadastrar como microempreendedores individuais (MEI), podendo ser tanto pessoas físicas, como pessoas jurídicas (Zettermann \& Vergara, 2017).

A mais recente legislação sobre guias de turismo no Brasil é a Portaria Mtur $\mathrm{n}^{\mathrm{o}}$ 27 de 2014, que estabeleceu normas que disciplinam o exercício da atividade de forma organizada, em uma espécie de "código do guia de turismo" (Zettermann \& Vergara, 2017). Ao mesmo tempo, afirma que a qualidade dos serviços prestados pode tornar o destino mais competitivo, e a qualificação dos recursos humanos é determinante para isso.

O profissionalismo no setor de serviços é determinante para a competitividade dos destinos turísticos asiáticos (Ap e Wong, 2001). Por isso, Lin, Lin e Chen (2017) afirmam que a qualidade do serviço prestado pelo guia de turismo está diretamente relaciona à satisfação do cliente com o serviço de viagem como um todo. "Enfim, por todas suas funções e atribuições, esse profissional torna-se um vendedor em potencial" (Nascimento et al 2014, p. 27). No entanto, mesmo diante da relevância da atividade profissional do guia de turismo, são escassas as pesquisas e publicações sobre tema justificando a exploração a seguir.

\section{METODOLOGIA}

No que diz respeito aos métodos de coleta de dados, além da revisão sistemática da literatura, para identificar pesquisas importantes sobre o assunto em estudo (Veal, 2011).

A fim de entender como o guia de turismo é abordado nas pesquisas científicas brasileiras, realizou-se um levantamento sistematizado nas publicações sobre guias de turismo em periódicos acadêmicos brasileiros de turismo. Foram consideradas todas as publicações online nas revistas desde suas fundações.

Os dados primários utilizados nas análises desta pesquisa foram todos coletados diretamente dos artigos selecionados, extraídos dos websites de cada uma das revistas. Após a seleção dos artigos, foi realizada uma análise sistemática dos documentos, orientada para se identificar as formas como o guia de turismo era 
retratado, caracterizado e contextualizado, além do reconhecimento dos autores, revistas, ano de publicação, palavras-chaves, resumos e lista de referências. Em seguida, realizou-se uma tabulação dos dados obtidos, facilitando as análises sequentes.

A seleção das revistas iniciou-se com a busca na lista de classificação de periódicos Qualis-CAPES de 2017, utilizando-se como filtro de pesquisa a área de avaliação "Administração, Ciências Contábeis e Turismo". Entre todas as revistas listadas no documento, elegeram-se apenas os extratos "A" e "B", em todos os seus subníveis. Entre os resultados encontrados, selecionaram-se os periódicos nacionais que tratassem diretamente de turismo e fossem open access. Dessa maneira, o universo de periódicos considerados para essa pesquisa foi de 25 revistas.

Em cada um desses periódicos, realizou-se a busca pelos termos "guia de turismo" e "guias de turismo" nos campos: título, resumo e todos os campos de termos de indexação, com a finalidade de encontrar artigos que contivessem, no mínimo, um desses termos no título e/ou resumo e/ou palavra-chave. Optou-se pelo uso das aspas duplas para recuperação dos termos exatos, excluindo, assim, pesquisas sobre guias turísticos, por exemplo.

Entre os resultados das buscas, consideram-se as edições regulares, especiais e dossiês dos periódicos. Por fim, foram selecionados apenas artigos científicos em língua portuguesa. Dessa forma, o universo de artigos científicos em língua portuguesa, publicados nos periódicos nacionais dos extratos "A" e "B" da QualisCAPES e que possuem os termos "guia de turismo" ou "guias de turismo" em seus títulos, resumos ou palavras-chaves, foi composto por 22 documentos.

Em um primeiro momento, cada artigo foi analisado previamente, e os dados foram compilados e trabalhados por meio do Microsoft Excel, para verificação de atendimento aos requisitos acima descritos. A planilha era composta pela identificação da revista, título da publicação, autores, ano de publicação, resumo, palavras-chaves e referências.

No segundo momento, os artigos foram lidos e analisados individualmente, para compreensão de seus conteúdos, enfoques e contextos. Após tais análises e tabulações, têm-se os resultados apresentados a seguir.

\section{ANÁLISE E DISCUSSÃo dOS RESULTADOS}

Pelos procedimentos metodológicos descritos no item anterior, foram selecionados para análise os artigos relacionados no Quadro 1. 
Quadro 1 - Artigos científicos selecionados para análise

\begin{tabular}{|c|c|c|c|c|}
\hline Título do Artigo & Autores & $\begin{array}{c}\text { Ano de } \\
\text { publicação }\end{array}$ & Periódico & $\begin{array}{c}\text { Onde consta o } \\
\text { termo "guia (s) de } \\
\text { turismo" }\end{array}$ \\
\hline $\begin{array}{l}\text { Guia de Turismo: o Mérito da } \\
\text { Profissão }\end{array}$ & Canani, I. S. S. & 1999 & Turismo em Análise & $\begin{array}{c}\text { Título } \\
\text { Resumo } \\
\text { Palavra-chave }\end{array}$ \\
\hline $\begin{array}{l}\text { A influência das leis trabalhistas } \\
\text { brasileiras na r relação } \\
\text { capital/trabalho dos guias de } \\
\text { turismo }\end{array}$ & $\begin{array}{l}\text { Julião, D. } \\
\text { Cortês, F. } \\
\text { Farias, J. M. S. } \\
\text { Lohman, J. } \\
\text { Silva, T. C. }\end{array}$ & 2009 & $\begin{array}{l}\text { Revista Acadêmica } \\
\text { Observatório de } \\
\text { Inovação do Turismo }\end{array}$ & $\begin{array}{c}\text { Título } \\
\text { Resumo } \\
\text { Palavra-chave }\end{array}$ \\
\hline $\begin{array}{l}\text { Determinantes do Valor } \\
\text { Percebido e da Intenção de } \\
\text { Retorno no Turismo Receptor } \\
\text { Brasileiro }\end{array}$ & $\begin{array}{l}\text { Santos, G. E. O. } \\
\text { Vassalo, M. D. } \\
\text { Rabahy, W. A. }\end{array}$ & 2009 & $\begin{array}{l}\text { Revista Brasileira de } \\
\text { Pesquisa em Turismo }\end{array}$ & Resumo \\
\hline $\begin{array}{l}\text { Guias de Turismo de Salvador: } \\
\text { Olhares sobre a Profissão e } \\
\text { Reflexões Sobre o Papel do Guia } \\
\text { como Sujeito da Cidade }\end{array}$ & Leme, F. B. M. & 2010 & $\begin{array}{c}\text { Revista de Cultura e } \\
\text { Turismo }\end{array}$ & $\begin{array}{c}\text { Título } \\
\text { Resumo } \\
\text { Palavra-chave }\end{array}$ \\
\hline $\begin{array}{l}\text { A atuação do guia de turismo em } \\
\text { Mato Grosso do Sul: diagnóstico, } \\
\text { aspectos conceituais } \\
\text { perspectivas para o segmento }\end{array}$ & $\begin{array}{l}\text { Nascimento, A. } \\
\text { O. } \\
\text { Silva, L. F. } \\
\text { Grechi, D. C. }\end{array}$ & 2014 & Revista Hospitalidade & $\begin{array}{c}\text { Título } \\
\text { Resumo } \\
\text { Palavra-chave }\end{array}$ \\
\hline $\begin{array}{l}\text { Estratégias para } \\
\text { fortalecimento do Geoturismo } \\
\text { no Atrativo Turístico Gruta do } \\
\text { Lago Azul, Bonito (MS) }\end{array}$ & $\begin{array}{l}\text { Oliveira, M. D. } \\
\text { Silva, L.F. }\end{array}$ & 2014 & Turismo Visão e Ação & Resumo \\
\hline $\begin{array}{l}\text { A Favela Santa Marta e seus } \\
\text { guias de turismo: identidade, } \\
\text { mobilização e conflito }\end{array}$ & Barbosa, G. F. & 2015 & $\begin{array}{c}\text { Revista Iberoamericana } \\
\text { de Turismo }\end{array}$ & Título \\
\hline $\begin{array}{l}\text { Dinâmicas do processo de } \\
\text { governança e coordenação dos } \\
\text { agentes que compóem um } \\
\text { destino de turismo sustentável, } \\
\text { no Centro-Oeste brasileiro }\end{array}$ & $\begin{array}{l}\text { Mariani, M. A. } \\
\text { P. } \\
\text { Arruda, D. O. } \\
\text { Malta, M. C. M. }\end{array}$ & 2015 & $\begin{array}{c}\text { Revista Brasileira de } \\
\text { Ecoturismo }\end{array}$ & Resumo \\
\hline $\begin{array}{l}\text { Formação técnica e superior em } \\
\text { turismo e hospitalidade no Rio } \\
\text { de Janeiro }\end{array}$ & $\begin{array}{l}\text { Algemiro, M. } \\
\text { Rejowski, M. }\end{array}$ & 2015 & $\begin{array}{l}\text { Revista de Turismo } \\
\text { Contemporâneo }\end{array}$ & Resumo \\
\hline $\begin{array}{l}\text { Geoparque como forma de } \\
\text { gestão } \\
\text { territorial } \\
\text { interdisciplinar apoiada no } \\
\text { geoturismo: caso do Projeto } \\
\text { Geoparque Seridó }\end{array}$ & $\begin{array}{l}\text { Nascimento, M. } \\
\text { A. L. } \\
\text { Gomes, C. S. C. } \\
\text { D. } \\
\text { Soares, A. S. }\end{array}$ & 2015 & $\begin{array}{c}\text { Revista Brasileira de } \\
\text { Ecoturismo }\end{array}$ & Resumo \\
\hline $\begin{array}{l}\text { O Desenvolvimento de } \\
\text { Competências na Formação de } \\
\text { Guia de Turismo a partir da } \\
\text { Percepção de Profissionais } \\
\text { Formados no Rio Grande do Sul }\end{array}$ & Abreu, C. V. & 2015 & $\begin{array}{l}\text { Revista Turismo } \\
\text { Estudos e Práticas }\end{array}$ & $\begin{array}{c}\text { Título } \\
\text { Resumo } \\
\text { Palavra-chave }\end{array}$ \\
\hline $\begin{array}{l}\text { O que visitar em Paris durante a } \\
\text { exposição Universal de 1878: } \\
\text { um guia turístico para geólogos }\end{array}$ & $\begin{array}{l}\text { Lopes, M. M. } \\
\text { Matos, A. C. }\end{array}$ & 2015 & $\begin{array}{l}\text { Revista Iberoamericana } \\
\text { de Turismo }\end{array}$ & Resumo \\
\hline $\begin{array}{l}\text { Elaboração e aplicação de uma } \\
\text { rota de trekking em uma área do } \\
\text { Parque Nacional da Serra da } \\
\text { Canastra }\end{array}$ & $\begin{array}{c}\text { Andrade, C. O. } \\
\text { P. } \\
\text { Carvalho, R. C. } \\
\text { R. } \\
\text { Godinho, R. F. } \\
\text { Magri, R. A. F. }\end{array}$ & 2016 & $\begin{array}{c}\text { Revista Brasileira de } \\
\text { Ecoturismo }\end{array}$ & Resumo \\
\hline $\begin{array}{lcc}\text { Os Produtos } & \text { Turísticos } & \text { de } \\
\text { Curitiba, PR, } & \text { Brasil } & \text { na } \\
\text { Perspectiva de } & \text { Gestores } & \text { de } \\
\text { Agências de Turismo Receptivo }\end{array}$ & $\begin{array}{l}\text { Pazini, R. } \\
\text { Gândara, J. M. } \\
\text { G. }\end{array}$ & 2016 & Turismo em Análise & Resumo \\
\hline $\begin{array}{l}\text { O Guia de Turismo: Uma } \\
\text { Abordagem Legal Sobre uma } \\
\text { Profissão no Brasil }\end{array}$ & $\begin{array}{l}\text { Zettermann, G. } \\
\text { D. } \\
\text { Vergara, } \\
\text { L. G. L. }\end{array}$ & 2017 & Turismo Visão e Ação & $\begin{array}{c}\text { Título } \\
\text { Resumo } \\
\text { Palavra-chave }\end{array}$ \\
\hline $\begin{array}{l}\text { A importância do guia de } \\
\text { turismo na experiência turística: } \\
\text { da teoria à prática das agências } \\
\text { de receptivo de Curitiba -PR }\end{array}$ & $\begin{array}{l}\text { Pazini, R. } \\
\text { Braga, D. C. } \\
\text { Gândara, } \\
\text { J. M. G. }\end{array}$ & 2017 & $\begin{array}{c}\text { Caderno Virtual de } \\
\text { Turismo }\end{array}$ & $\begin{array}{c}\text { Título } \\
\text { Resumo } \\
\text { Palavra-chave }\end{array}$ \\
\hline
\end{tabular}

(continua...) 


\section{Quadro 1- Continuação}

\begin{tabular}{|c|c|c|c|c|}
\hline Título do Artigo & Autores & $\begin{array}{c}\text { Ano de } \\
\text { publicação }\end{array}$ & Periódico & $\begin{array}{c}\text { Onde consta o } \\
\text { termo "guia }(s) \text { de } \\
\text { turismo" }\end{array}$ \\
\hline $\begin{array}{l}\text { Análise da Qualidade do Serviço: } \\
\text { um estudo entre a percepção do } \\
\text { cliente e do guia em roteiros } \\
\text { regionais do SESC - Santa } \\
\text { Catarina, Brasil }\end{array}$ & $\begin{array}{l}\text { Soares, M. H. A. } \\
\text { Ardigó, C. M. } \\
\text { Melo Filho, M. } \\
\text { E. S. }\end{array}$ & 2017 & Turismo em Análise & $\begin{array}{c}\text { Resumo } \\
\text { Palavra-chave }\end{array}$ \\
\hline $\begin{array}{l}\text { Percepção dos atores sociais do } \\
\text { turismo sobre o pulso de } \\
\text { inundação do Pantanal (MT) }\end{array}$ & $\begin{array}{l}\text { Rabelo, M. T. O. } \\
\text { Arts, K. A. J. } \\
\text { Girard, P. } \\
\text { Ioris, A. A. R. } \\
\text { Figueiredo, D. } \\
\text { M. }\end{array}$ & 2017 & $\begin{array}{c}\text { Revista Brasileira de } \\
\text { Ecoturismo }\end{array}$ & Resumo \\
\hline $\begin{array}{l}\text { Práticas turísticas por meio da } \\
\text { análise da dimensão ambiental } \\
\text { em geossítios do Projeto } \\
\text { Geoparque Seridó (RN) }\end{array}$ & $\begin{array}{l}\text { Medeiros, J. L. } \\
\text { Nascimento, M. } \\
\text { A. L. } \\
\text { Perinotto, A. R. } \\
\text { C. }\end{array}$ & 2017 & $\begin{array}{l}\text { Revista Brasileira de } \\
\text { Ecoturismo }\end{array}$ & Resumo \\
\hline $\begin{array}{l}\text { Apontamentos históricos sobre } \\
\text { a profissão do guia de turismo }\end{array}$ & $\begin{array}{l}\text { Meira, C. M. } \\
\text { Kushano, E. S } \\
\text { Hintze, H. C. }\end{array}$ & 2018 & $\begin{array}{l}\text { Revista de Turismo } \\
\text { Contemporâneo }\end{array}$ & $\begin{array}{c}\text { Título } \\
\text { Resumo } \\
\text { Palavra-chave }\end{array}$ \\
\hline $\begin{array}{l}\text { Experimentando } \\
\text { conhecimento: o Turismo } \\
\text { Pedagógico como ferramenta } \\
\text { para o Ensino Profissional }\end{array}$ & $\begin{array}{l}\text { Louzeiro, F. O. } \\
\text { S. }\end{array}$ & 2019 & $\begin{array}{l}\text { Revista Brasileira de } \\
\text { Ecoturismo }\end{array}$ & Resumo \\
\hline $\begin{array}{l}\text { Avaliação Preliminar de Risco } \\
\text { (APR) em atividades } \\
\text { ecoturísticas na trilha do Pico da } \\
\text { Tijuca, Parque Nacional da } \\
\text { Tijuca (RJ) }\end{array}$ & $\begin{array}{l}\text { Neves, C. R. F. } \\
\text { Costa, V. C. }\end{array}$ & 2019 & $\begin{array}{l}\text { Revista Brasileira de } \\
\text { Ecoturismo }\end{array}$ & Resumo \\
\hline
\end{tabular}

Observa-se que, aproximadamente, $36,4 \%$ dos artigos mencionam guias de turismo em todas as categorias analisadas: título, resumo e palavra-chave. Outros $54,5 \%$ só os citam nos resumos, enquanto $4,5 \%$ apenas no título e 4,5\% no resumo e nas palavras-chaves. Tal resultado representa um indicativo da abordagem dos artigos sobre esses profissionais.

Aqueles que os citam em todas as categorias $(36,4 \%)$ têm uma tendência a discutir o guia de turismo como foco do estudo, ao mesmo tempo em que os que apenas indexaram os guias nos resumos ou palavras-chaves ou títulos, tratam o profissional ou a atividade como coadjuvante do estudo realizado.

Ao relacionar a autoria e coautoria dos artigos analisados, percebe-se que 47 autores publicaram apenas um trabalho sobre essa temática, e quatro autores publicaram dois trabalhos cada (Silva, 2014a, 2014b; Nascimento, 2015, 2017, Gândara, 2016, 2017; Pazini, 2016, 2017), construindo um grupo de 51 autores / coautores que já publicaram sobre guias de turismo em revistas científicas nacionais. Podem-se conectar tais autores e trabalhos construindo uma rede de pesquisadores que trataram sobre o tema, conforme consta na Figura 2. 
Figura 2 - Redes de autores

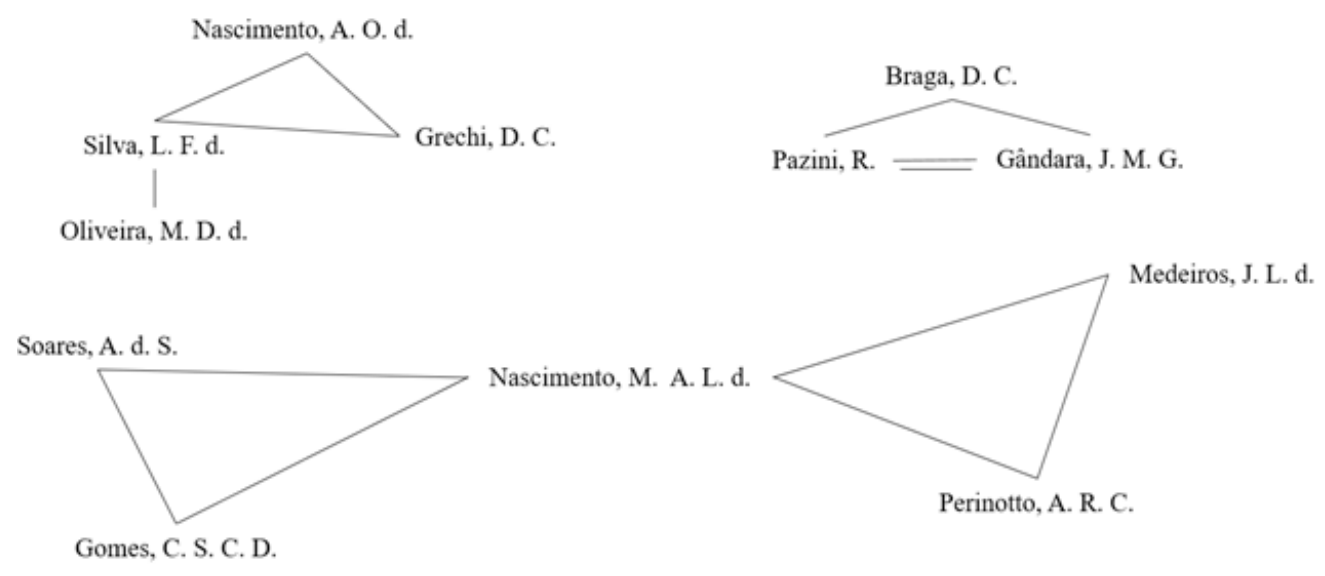

Fonte - Autores (2020)

Percebe-se que essa rede está organizada em três núcleos, que não se relacionam entre si, mas abrangem $27 \%$ dos artigos analisados. Outra característica importante sobre essa rede é a data de publicação de seus artigos que abrange o período de 2014-2017, o que indica o alto grau de prematuridade, isto é, antes de 2014 não havia autores de artigos que tivessem publicado mais de uma vez sobre os guias de turismo. Isso pode sinalizar que as pesquisas sobre esse profissional/profissão são descontinuadas.

Ao separar os artigos analisados pelo ano de publicação, tem-se o gráfico 1, onde há um crescimento linear das publicações sobre o tema. 0 primeiro artigo publicado sobre guias de turismo foi em 1999, na Revista Turismo em Análise (RTA), e discursava justamente sobre os méritos dessa profissão que, até então, havia sido ignorada pela pesquisa científica. 0 fato de o estudo ter sido publicado pela RTA é bastante esclarecedor, pois se percebe que, entre as revistas estudadas, existiam apenas três naquele ano.

Gráfico 1 - Artigos que abordam a temática do guia de turismo ao longo dos anos

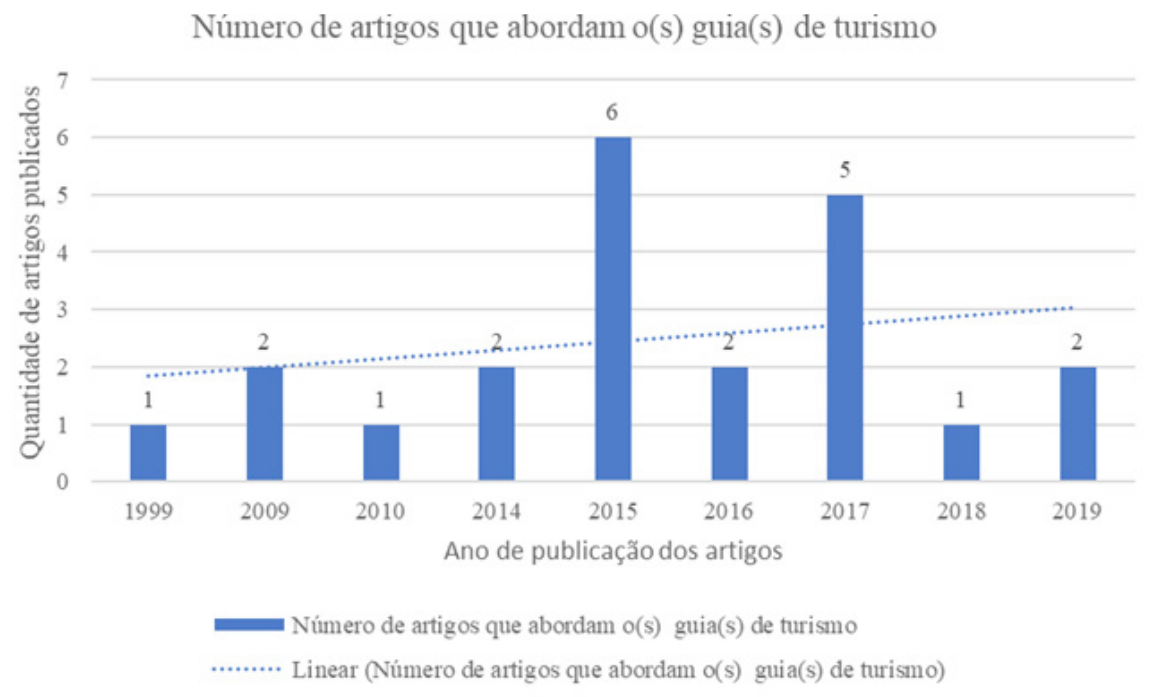

Fonte - Autores (2020) 
Nota-se um pico de publicações sobre os guias de turismo no ano de 2015. Esses estudos representam, aproximadamente, $27 \%$ da amostra analisada. Em 2017, o número de artigos aproximou-se desse pico, mas são desconhecidas as razões para esse aumento significativo de publicações nos anos de 2015 e 2017, com quedas abruptas nos anos subsequentes.

Ao analisar a amostra pelas revistas que publicaram os estudos, percebese que, das 25 revistas pesquisadas, apenas 11 (44\%) publicaram sobre guias de turismo, ou seja, menos da metade das revistas científicas brasileiras contemplaram publicações sobre essa temática. Dentre essas 11 revistas, que apresentaram resultados das buscas, seis publicaram apenas um artigo, enquanto a Revista Brasileira de Ecoturismo (RBEcotur) publicou sete artigos sobre a mesma temática, talvez, em razão da reconhecida necessidade dos guias em atividades ecoturísticas. A primeira revista cientifica de turismo no Brasil, Revista Turismo em Análise (RTA), foi a segunda que mais tratou sobre os guias de turismo, ou seja, juntas, a RBEcotur e a RTA representam $45 \%$ da amostragem. 0 número de artigos encontrados em cada periódico pesquisado encontra-se na Tabela 1.

Tabela 1 - Quantidade de artigos publicados sobre a temática dos guias de turismo, por revista

\begin{tabular}{|l|c|}
\hline \multicolumn{1}{c}{$\quad$ Periódico } & Número de artigos encontrados \\
\hline Revista Brasileira de Ecoturismo & 7 \\
\hline Revista Turismo em Análise & 3 \\
\hline Revista de Turismo Contemporâneo & 2 \\
\hline Revista Iberoamericana de Turismo & 2 \\
\hline Revista Turismo, Visão e Ação & 2 \\
\hline Caderno Virtual de Turismo & 1 \\
\hline Revista Acadêmica Observatório de Inovação do Turismo & 1 \\
\hline Revista Brasileira de Pesquisa em Turismo & 1 \\
\hline Revista de Cultura e Turismo & 1 \\
\hline Revista Hospitalidade & 1 \\
\hline Revista Turismo Estudos e Práticas & 1 \\
\hline Total & 22 \\
\hline
\end{tabular}

Fonte - Autores (2020)

Outra forma de investigação possibilitada pela amostra de artigos encontrados é por suas palavras-chaves. Há aqueles que mencionaram "guia(s) de turismo" entre as palavras-chave apresentadas, mas há aqueles que, mesmo falando sobre o assunto, não a mencionaram. Este é um importante exercício para perceber com quais temas os guias de turismo são relacionados nas pesquisas científicas. Por meio do software ATLAS.ti, construiu-se a nuvem de palavras-chaves apresentada na Figura 3. 
Figura 3 - Nuvem de palavras-chaves encontradas nos artigos analisados

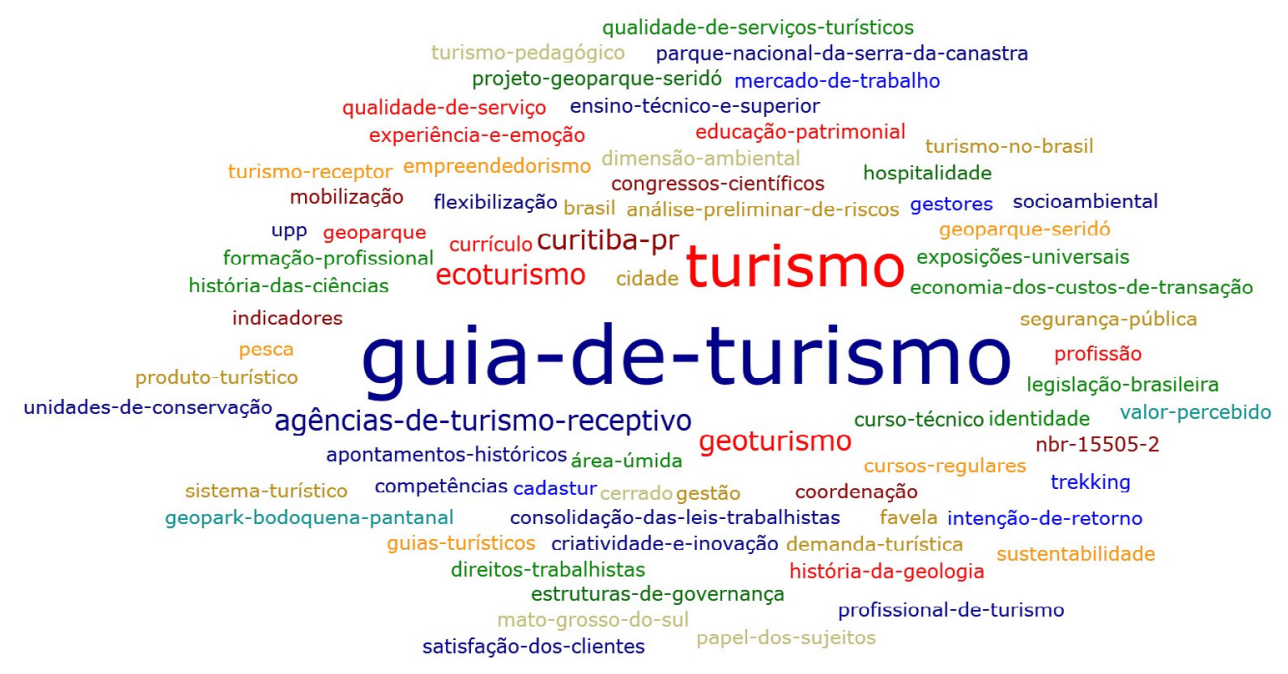

Fonte - Autores (2020)

Utilizou-se do conector hífen (-) para ligar as palavras-chaves compostas, a fim de só somar as sentenças realmente iguais. Ao relacionar as palavras-chaves dos 22 artigos estudados, encontrou-se uma variedade de 72 termos e é importante notar que não houve uma palavra-chave comum a todos os artigos. Porém, conforme o esperado, o termo mais mencionado foi "guia de turismo", repetido nove vezes, e por isso encontra-se no centro da nuvem. A segunda palavrachave mais utilizada foi "turismo", mencionada em seis dos artigos. Em terceiro lugar, os termos mais comuns como palavras-chaves foram "agências de turismo receptivo", "Curitiba-PR", "geoturismo" e "ecoturismo", todos empregados duas vezes. Todas as demais palavras-chaves (66) foram mencionadas em apenas um artigo da amostra e encontram-se nos limites da nuvem.

Os dois termos mais utilizados como palavras-chaves (guia de turismo e turismo) eram esperados em razão da temática da pesquisa e das revistas que foram analisadas, porém os outros termos apresentam um raso indicativo dos temas com os quais as pesquisas sobre guias de turismo se relacionam: agências e ecoturismo.

Outra relação possível, na primeira análise dos artigos selecionados, diz respeito às referências bibliográficas, pois, assim, pode-se perceber quais são as mais utilizadas para embasar as discussões sobre o tema. Em razão disso, ao agrupar todas as referências dos 22 artigos estudados, verifica-se um repertório de 540 obras, entre elas, artigos, livros, capítulos de livros, legislações, entre outros.

Entre essas, a maior parte, 497 obras, foi referenciada apenas uma vez, notadamente, por se tratar de temas específicos de cada estudo. Outros 36 trabalhos foram utilizados como referências de dois artigos estudados. Por fim, o conjunto mais citado é composto por sete referências, especificadas no Quadro 02 . 
Quadro 2 - Conjunto de obras mais citadas nos artigos estudados

\begin{tabular}{|l|c|c|}
\multicolumn{1}{|c}{ Título } & Autores (Ano) & $\begin{array}{c}\text { No de artigos que } \\
\text { utilizaram a referência }\end{array}$ \\
\hline Análise estrutural do turismo & Beni (1998) & 7 \\
\hline $\begin{array}{l}\text { Lei no 8.623, de 28 de janeiro de 1993 } \\
\text { Decreto no 946, de 10 de outubro de } \\
\text { 1993. }\end{array}$ & Embratur (1993) & 6 \\
\hline $\begin{array}{l}\text { Portaria MTur no 27, de 30 de janeiro } \\
\text { de 2014 }\end{array}$ & Ministério do Turismo (2014) & 5 \\
\hline $\begin{array}{l}\text { Resolução Normativa CNTur n. o 04/83. } \\
\text { Guia de turismo: o mérito da profissão. }\end{array}$ & Conselho Nacional de Turismo (1983) & 4 \\
\hline Catálogo Nacional dos Cursos Técnicos & Canani (1999) & 3 \\
\hline & Fonte - Autores (2020) & 3 \\
\hline
\end{tabular}

Nota-se a predominância de legislações, em razão da necessidade de embasamento normativo para os estudos sobre guias de turismo no Brasil, uma vez que essa é a única atividade profissional reconhecida e regulamentada na área do turismo, e este é, muitas vezes, um dos principais argumentos sobre a importância desse profissional.

O estudo de Canani (1999) foi o primeiro artigo sobre o tema, publicado nas revistas nacionais e, além de ser um dos objetos desta pesquisa, é consolidado como uma das referências centrais sobre o tema. 0 catálogo nacional de cursos técnicos aparece como uma das referências mais utilizadas, principalmente, por ser uma profissão de nível técnico e pelas normativas exigirem formação específica, no que diz respeito à carga horária e à grade curricular, para o credenciamento dos profissionais. Podem-se, portanto, indicar tais referências (Quadro 02) como as principais fontes de pesquisa para os autores sobre a temática no país.

Nas análises dos artigos, pode-se compreender como os guias de turismo são tratados nos estudos científicos. As publicações são organizadas em cinco grandes grupos: (1) o guia como protagonista do estudo; (2) o guia como recurso metodológico; (3) o guia de turismo inserido no mercado turístico receptivo; (4) o guia de turismo como resultado de alguma ação; e, por fim, (5) o guia de turismo como sinônimo de guia turístico.

0 primeiro grupo reúne aqueles estudos em que a atividade profissional dos guias de turismo é protagonista, ou seja, o profissional e/ou a profissão são os objetos centrais da pesquisa. Nessa categoria, enquadram-se os seguintes trabalhos:

Quadro 3 - Grupo 1 - 0 guia como protagonista do estudos

\begin{tabular}{|c|c|c|}
\hline Aut & 'ítulo & Objetivo(s) \\
\hline Canan & $\begin{array}{l}\text { Guia de Turismo: o Mérito da } \\
\text { Profissão }\end{array}$ & $\begin{array}{l}\text { Mostrar a importância do exercício da profissão de } \\
\text { guia de turismo no Brasil e sua relação com a } \\
\text { qualidade nos serviços turísticos }\end{array}$ \\
\hline $\begin{array}{l}\text { Jul } \\
\text { Far } \\
\& S\end{array}$ & $\begin{array}{l}\text { A influência das leis traball } \\
\text { brasileiras na re } \\
\text { capital/trabalho dos guias de tur }\end{array}$ & $\begin{array}{l}\text { estões referentes à relação ent } \\
\text { al no âmbito da atividade turística q } \\
\text { a atividade profissional do guia }\end{array}$ \\
\hline Le & $\begin{array}{l}\text { Guias de turismo de Salvador: } \\
\text { Olhares sobre a profissão e reflexões } \\
\text { sobre o papel do guia como sujeito na } \\
\text { cidade }\end{array}$ & $\begin{array}{l}\text { Compreender as funções atribuídas aos guias de } \\
\text { turismo, as percepções desse profissional e suas } \\
\text { influências na formação e desenvolvimento de um } \\
\text { mercado turístico }\end{array}$ \\
\hline
\end{tabular}

(continua...) 


\section{Quadro 3 - Continuação}

\begin{tabular}{|c|c|c|}
\hline Autores (Ano) & Título & Objetivo(s) \\
\hline $\begin{array}{l}\text { Nascimento, } \\
\text { Silva \& Grechi } \\
\quad \text { (2014) }\end{array}$ & $\begin{array}{l}\text { A atuação do guia de turismo em } \\
\text { Mato Grosso do Sul: diagnóstico, } \\
\text { aspectos conceituais e perspectivas } \\
\text { para o segmento }\end{array}$ & $\begin{array}{l}\text { Analisar a inserção e importância do guia de turismo } \\
\text { no mercado de trabalho }\end{array}$ \\
\hline Abreu (2015) & $\begin{array}{l}\text { O desenvolvimento de competências } \\
\text { na formação de guias de turismo a } \\
\text { partir da percepção de profissionais } \\
\text { formados no Rio Grande do Sul }\end{array}$ & $\begin{array}{l}\text { Analisar a percepção dos guias de turismo sobre o } \\
\text { desenvolvimento de suas competências ao final da } \\
\text { formação profissional técnica }\end{array}$ \\
\hline $\begin{array}{c}\text { Zettermann \& } \\
\text { Vergara (2017) }\end{array}$ & $\begin{array}{l}\text { O guia de turismo: uma abordagem } \\
\text { legal sobre uma profissão no Brasil }\end{array}$ & $\begin{array}{l}\text { Identificar a situação do guia de turismo no Brasil, por } \\
\text { meio de uma abordagem da legislação existente }\end{array}$ \\
\hline $\begin{array}{l}\text { Soares, Ardigó } \\
\text { \& Melo (2017) }\end{array}$ & $\begin{array}{l}\text { Análise da Qualidade do Serviço: um } \\
\text { estudo entre a percepção do cliente e } \\
\text { do guia em roteiros regionais do } \\
\text { SESC - Santa Catarina, Brasil }\end{array}$ & $\begin{array}{l}\text { Analisar a qualidade percebida pelos clientes em } \\
\text { relação aos serviços prestados pelos guias de turismo }\end{array}$ \\
\hline $\begin{array}{l}\text { Meira, Kushano } \\
\text { \& Hintze } \\
\text { (2018) }\end{array}$ & $\begin{array}{l}\text { Apontamentos históricos sobre a } \\
\text { profissão do guia de turismo }\end{array}$ & $\begin{array}{l}\text { Apresentar o panorama históricos e aspectos legais a } \\
\text { formação e profissionalização do guia de turismo com } \\
\text { enfoque no Brasil }\end{array}$ \\
\hline
\end{tabular}

Fonte - Autores (2020)

O segundo grupo é composto por trabalhos que utilizam esse profissional como recurso metodológico, compondo a amostra da pesquisa de campo, por exemplo. São agrupados nessa categoria os seguintes trabalhos:

\section{Quadro 4 - Grupo 2 - 0 guia como recurso metodológico}

\begin{tabular}{|c|c|c|}
\hline Autores (Ano) & Título & Objetivo(s) \\
\hline $\begin{array}{l}\text { Oliveira \& Silva } \\
\text { (2014) }\end{array}$ & $\begin{array}{l}\text { Estratégias para o fortalecimento do } \\
\text { geoturismo no atrativo turístico } \\
\text { Gruta do Lago Azul Bonito MS }\end{array}$ & $\begin{array}{l}\text { Identificar as ações de fortalecimento para o } \\
\text { geoturismo em um atrativo turístico, a fim de } \\
\text { possibilitar essa identificação uma série de atores } \\
\text { compôs a amostra entrevistada, entre eles, os guias de } \\
\text { turismo }\end{array}$ \\
\hline $\begin{array}{l}\text { Rabelo, Arts, } \\
\text { Girard, Ioris, \& } \\
\text { Figueiredo } \\
\text { (2017) }\end{array}$ & $\begin{array}{l}\text { Práticas turísticas por meio da } \\
\text { análise da dimensão ambiental em } \\
\text { geossítios do Projeto Geoparque } \\
\text { Seridó (RN) }\end{array}$ & $\begin{array}{l}\text { Analisar como os diferentes atores sociais de um } \\
\text { destino turístico percebem um fenômeno específico } \\
\text { na localidade, o guia de turismo, por ser um desses } \\
\text { atores, compuseram a amostragem }\end{array}$ \\
\hline $\begin{array}{l}\text { Medeiros, } \\
\text { Nascimento \& } \\
\text { Perinotto } \\
\text { (2017) }\end{array}$ & $\begin{array}{l}\text { Percepção dos atores sociais do } \\
\text { turismo sobre o pulso de inundação } \\
\text { do Pantanal (MT) }\end{array}$ & $\begin{array}{l}\text { Analisar a situação ambiental em um Geoparque, os } \\
\text { guias de turismo e outros agentes locais foram parte } \\
\text { do contexto estudado }\end{array}$ \\
\hline $\begin{array}{l}\text { Louzeiro } \\
\text { (2019) }\end{array}$ & $\begin{array}{l}\text { Experimentando o conhecimento: o } \\
\text { Turismo Pedagógico } r \text { como } \\
\text { ferramenta para o } \\
\text { Profissional }\end{array}$ & $\begin{array}{l}\text { Analisar os efeitos decorrentes da participação em } \\
\text { atividades práticas no âmbito do turismo. } 0 \text { público- } \\
\text { alvo das pesquisas foram alunos do curso de guia de } \\
\text { turismo. }\end{array}$ \\
\hline $\begin{array}{c}\text { Neves \& Costa } \\
\text { (2019) }\end{array}$ & $\begin{array}{l}\text { Avaliação Preliminar de Risco (APR) } \\
\text { em atividades ecoturísticas na trilha } \\
\text { do Pico da Tijuca, Parque Nacional da } \\
\text { Tijuca (RJ) }\end{array}$ & $\begin{array}{l}\text { Analisar e mensurar quais os riscos ambientais e de } \\
\text { segurança que os visitantes estão sujeitos ao } \\
\text { realizarem caminhadas em determinada trilha, para } \\
\text { tanto, os guias de turismo foram entrevistados e } \\
\text { auxiliaram os pesquisadores. }\end{array}$ \\
\hline
\end{tabular}

Fonte - Autores (2020)

O terceiro grupo de estudos é composto por aqueles cujo foco é o mercado turístico receptivo e o guia de turismo, por integrá-lo, participa da pesquisa. Nessa categoria, enquadram-se os seguintes trabalhos: 
Quadro 5 - Grupo 3 - 0 guia de turismo inserido no mercado turístico receptivo

\begin{tabular}{|c|c|c|}
\hline $\begin{array}{c}\text { Autores } \\
\text { (Ano) }\end{array}$ & Título & Objetivo(s) / Resultado(s) \\
\hline $\begin{array}{l}\text { Santos, } \\
\text { Vassalo \& } \\
\text { Rabahy } \\
\text { (2009) }\end{array}$ & $\begin{array}{l}\text { Determinantes do valor } \\
\text { percebido e da intenção de } \\
\text { retorno no turismo receptor } \\
\text { brasileiro }\end{array}$ & $\begin{array}{l}\text { Estudar o valor percebido do produto turístico brasileiro e sua } \\
\text { relação com a intenção de retorno. A pesquisa estudou o } \\
\text { mercado receptivo e concluiu que um dos determinantes para a } \\
\text { qualidade do receptivo e intenção de retorno é o serviço } \\
\text { prestado pelos guias de turismo }\end{array}$ \\
\hline $\begin{array}{c}\text { Mariani, } \\
\text { Arruda \& } \\
\text { Malta (2015) }\end{array}$ & $\begin{array}{l}\text { Dinâmicas do processo de } \\
\text { governança e coordenação } \\
\text { dos agentes que compõem } \\
\text { um destino de turismo } \\
\text { sustentável, no Centro-Oeste } \\
\text { brasileiro }\end{array}$ & $\begin{array}{l}\text { Analisar as dinâmicas de coordenação e estruturas de } \\
\text { governança em um destino turístico, onde os guias de turismo, } \\
\text { como um dos agentes envolvidos, participam da pesquisa }\end{array}$ \\
\hline $\begin{array}{l}\text { Pazini \& } \\
\text { Gândara } \\
\text { (2016) }\end{array}$ & $\begin{array}{l}\text { Os Produtos Turísticos de } \\
\text { Curitiba, PR, Brasil na } \\
\text { Perspectiva de } \\
\text { Agências Gestores de } \\
\text { Receptivo }\end{array}$ & $\begin{array}{l}\text { Analisar os produtos comercializados pelas agências receptivas } \\
\text { em um destino, entre esses produtos, há o guia de turismo } \\
\text { inseridos no mercado receptivo }\end{array}$ \\
\hline $\begin{array}{l}\text { Pazini, Braga } \\
\text { \& Gândara } \\
\text { (2017) }\end{array}$ & $\begin{array}{l}\text { A importância do guia de } \\
\text { turismo na experiência } \\
\text { turística: da teoria à prática } \\
\text { das agências de receptivo de } \\
\text { Curitiba- PR }\end{array}$ & $\begin{array}{l}\text { Estudar a coerência entre discussões na academia e prática do } \\
\text { mercado turístico receptivo. } 0 \text { guia de turismo é visto como } \\
\text { parte desse sistema receptivo. E o resultado do seu trabalho } \\
\text { reflete diretamente na experiência turística }\end{array}$ \\
\hline
\end{tabular}

Fonte - Autores (2020)

O quarto agrupamento de estudos reúne aqueles em que a atividade profissional do guia de turismo é vista como resultado de uma série de ações, ou seja, cria-se demanda por guias ou se profissionaliza a atividade, em razão de outras ações. São agrupados nessa categoria os seguintes trabalhos:

Quadro 6 - Grupo 4 - 0 guia de turismo como resultado de algumas ações

\begin{tabular}{|c|c|c|}
\hline $\begin{array}{l}\text { Autores } \\
\text { (Ano) }\end{array}$ & Título & Objetivo(s) / Resultado(s) \\
\hline $\begin{array}{l}\text { Algemiro \& } \\
\text { Rejowski } \\
\text { (2015) }\end{array}$ & $\begin{array}{l}\text { Formação técnica e superior } \\
\text { em turismo e hospitalidade } \\
\text { no Rio de Janeiro }\end{array}$ & $\begin{array}{l}\text { Estudar a oferta de formação profissional em um destino } \\
\text { turístico, onde a do guia é uma das formações técnicas }\end{array}$ \\
\hline $\begin{array}{l}\text { Barbosa } \\
(2015)\end{array}$ & $\begin{array}{l}\text { A Favela Santa Marta e seus } \\
\text { guias de turismo: identidade, } \\
\text { mobilização e conflito }\end{array}$ & $\begin{array}{l}\text { Descrever o processo de constituição de um mercado turístico } \\
\text { receptivo em um destino. A formação e a atuação de guias são } \\
\text { decorrentes }\end{array}$ \\
\hline $\begin{array}{l}\text { Nascimento, } \\
\text { Gomes \& } \\
\text { Soares } \\
(2015)\end{array}$ & $\begin{array}{l}\text { Geoparque como forma de } \\
\text { gestão } \quad \text { territorial } \\
\text { interdisciplinar apoiada no } \\
\text { geoturismo: caso do Projeto } \\
\text { Geoparque Seridó }\end{array}$ & $\begin{array}{l}\text { Apresentar a evolução do conceito de geoparque no Mundo e no } \\
\text { Brasil. A capacitação de guias de turismo é resultado de algumas } \\
\text { dessas ações }\end{array}$ \\
\hline $\begin{array}{l}\text { Andrade, } \\
\text { Carvalho, } \\
\text { Godinho \& } \\
\text { Magri (2016) }\end{array}$ & $\begin{array}{l}\text { Elaboração e aplicação de } \\
\text { uma rota de trekking em uma } \\
\text { área do Parque Nacional da } \\
\text { Serra da Canastra }\end{array}$ & $\begin{array}{l}\text { Criar e adequar um atrativo ecoturístico, com a } \\
\text { profissionalização dos guias }\end{array}$ \\
\hline
\end{tabular}

Fonte - Autores (2020)

Por fim, um quinto e último artigo analisado deve ser classificado separadamente, pois confunde guia de turismo com guia turístico, confusão habitual no senso comum e presente nas pesquisas científicas. Esse equívoco é inadmissível em publicações acadêmicas, denotando falta de rigor metodológica e conceitual em determinadas pesquisas. 
Quadro 7 - Grupo 5 - 0 guia de turismo como sinônimo de guia turístico

\begin{tabular}{|c|c|c|}
\hline $\begin{array}{c}\text { Autores } \\
\text { (Ano) }\end{array}$ & Título & Objetivo / Comentário \\
\hline $\begin{array}{c}\text { Lopes \& } \\
\text { Matos (2015) }\end{array}$ & $\begin{array}{l}\text { O que visitar em Paris } \\
\text { durante a Exposição } \\
\text { Universal de 1878: um guia } \\
\text { turístico para geólogos }\end{array}$ & $\begin{array}{l}\text { Comentar os guias turísticos elaborados para as exposições } \\
\text { universais. No entanto, ao longo do texto, os autores empregam } \\
\text { diversas vezes os termos guia de turismo e guia turístico como } \\
\text { sinônimos. }\end{array}$ \\
\hline \multicolumn{3}{|c|}{ Fonte - Autores (2020) } \\
\hline
\end{tabular}

No que se refere ao padrão de abordagem por revista, se reconhece que as temáticas estão sempre em relação aos escopos, no entanto, destaca-se a preferência da Revista Turismo em Análise pela publicação de artigos do grupo 1, uma vez que das três publicações sobre a temática dos guias de turismo, duas se enquadram na primeira categoria, que tem foco nessa atividade profissional. Este dado também tem relação com o tempo de atuação da revista e o apontamento de que as primeiras publicações da área são sobre essa temática mais focalizam o profissional.

Outra análise mostra que todos os estudos do segundo grupo, aquele que utiliza o guia de turismo como amostragem da pesquisa, estão publicados em estudos relacionados ao ecoturismo, enquanto os restantes das pesquisas ligadas ao ecoturismo pertencem ao grupo 4, no qual o guia aparece como reflexo de ações. Entende-se, portanto, que apesar da eminente necessidade de um guia de turismo para atividades ecoturísticas, os autores da área utilizam a atividade do guia como recorte metodológico, amostra ou entendem como reflexo de outras ações e, dificilmente, como protagonista da atividade ou pertencente a um mercado receptivo.

Por fim, constata-se que metade dos artigos do grupo 3, em que o guia de turismo está inserido no mercado receptivo, tem autores semelhantes, indicando uma abordagem preferida pelos autores ou pesquisas correlacionadas.

Entre os cinco grupos em que os 22 artigos analisados foram separados, notase que o primeiro, aquele em que o guia é apresentado como protagonista do estudo, é composto por oito artigos, indicando que 36\% dos artigos analisados apresentam o guia de turismo como elemento central de suas pesquisas, mais uma vez, evidenciando a importância de pesquisas sobre tal temática.

\section{CONCLUSÃo}

Os estudos sistemáticos possibilitam localizar e estudar as pesquisas científicas publicadas anteriormente sobre determinado tema, com isso se identifica o estado da arte do tema estudado, possibilitando análises, interpretações, categorizações e identificação de estudos fundamentais para a área.

$\mathrm{Na}$ produção deste artigo, identificam-se 22 pesquisas sobre a atividade profissional do guia de turismo, publicadas em revistas científicas nacionais. As análises realizadas mostram uma recente rede de autores que publicaram sobre a temática do guia de turismo. Além disso, pode-se construir uma nuvem com as palavras-chaves utilizadas nos artigos estudados, com as palavras mais citadas.

Ao relacionar as referências bibliográficas dos artigos estudos, nota-se que a maior parte delas (92\%) são citadas apenas uma vez, e, por isso, devem se tratar 
de temas específicos de cada um dos estudos. Elaborou-se um quadro com as sete obras mais citadas entre as referências relacionadas, apontando-as como as principais fontes de pesquisa para autores sobre a temática no país.

Observando-se as datas de publicação das pesquisas, nota-se que o primeiro artigo sobre o tema foi publicado em 1999, os anos seguintes apresentaram uma tendência de linearidade no crescente de publicações sobre o tema.

No que tange as abordagens que os estudos fazem do guia de turismo, foi possível a divisão da amostra em cinco grandes grupos: (1) o guia como protagonista do estudo; (2) o guia como recurso metodológico; (3) o guia de turismo inserido no mercado turístico receptivo; (4) o guia de turismo como resultado de alguma ação; e, por fim, (5) o guia de turismo como sinônimo de guia turístico.

Essa divisão em grupos permitiu algumas análises em que se constatou que os primeiros artigos publicados sobre a temática o abordam como protagonista do estudo. Outra constatação foi sobre os periódicos que publicaram os estudos, a Revista Brasileira de Ecoturismo é a que mais publicou, entretanto, esses estudos colocam o guia de turismo como coadjuvante da pesquisa, apesar da reconhecida necessidade de atuação desse profissional em atividades ecoturísticas.

Os objetivos desse levantamento foram alcançados, pois se vislumbra um panorama das pesquisas científicas brasileiras sobre a atividade profissional do guia de turismo, entendendo, o tratamento da acadêmica sobre esse profissional em suas pesquisas. Reconhece-se que é preciso ampliar a amostragem deste estudo, e, como alternativa, podem-se incluir teses, dissertações e livros sobre a mesma temática, além de levantamentos sobre publicações internacionais.

Ademais, ressalta-se também, a necessidade de estudos sobre a caracterização do trabalho dos guias de turismo, além daqueles apresentados nessa pesquisa, pois conforme discutido na analise dos grupos, aquelas pesquisas que se enquadram no Grupo 1 caracterizam-se como pesquisas descritivas da profissão e, no momento atual do mercado de trabalho, há necessidade de pesquisas e projetos que reflitam sobre as condições de trabalho desse profissional que ainda encontra-se marginalizado na atividade turística e pouco discutido nos estudos do meio.

\section{REFERÊNCIAS}

Abreu, C. V. (2015). O desenvolvimento de competências na formação de guias de turismo a partir da percepção de profissionais formados no Rio Grande do Sul. Revista Turismo - Estudos e Práticas, 4(1), 6-27.

Algemiro, M., \& Rejowski, M. (2015). Formação técnica e superior em turismo e hospitalidade no Rio de Janeiro. Revista de Turismo Contemporâneo, 3(2), 318-338.

Andrade, C. O. de P., Carvalho, R. de C. R., Godinho, R. F., \& Magri, R. A. F. (2016). Elaboração e aplicação de uma rota de trekking em uma área do Parque Nacional da Serra da Canastra. Revista Brasileira de Ecoturismo, 9(2), 285-307.

Ap, J., \& Wong, K. K. F. (2001). Case study on tour guiding : professionalism, issues and problems. Tourism Management, 22, 551-563. 
Barbosa, G. F. (2015). A Favela Santa Marta e seus guias de turismo: identidade, mobilização e conflito. Revista Iberoamericana de Turismo, 5, 169-179.

Brasil. Lei no 8.623, de 28 de janeiro de 1993. (1993). Brasília.

Brasil. Deliberação Normativa no 427, de 04 de outubro de 2001. (2001). Brasília - DF.

Brasil. Portaria do Ministério do Turismo no 130, de 26 de julho de 2011 (2011). Brasil.

Brasil. Portaria do Ministério do Turismo no 27, de 30 de janeiro de 2014. (2014). Brasília.

Brasil, M. do T. ([s.d.]). Cadastur. Recuperado em 22 de março de 2020, de https://cadastur. turismo.gov.br

Canini, I. S. S. (1999). Guia de turismo: o mérito da profissão. Revista Turismo em Análise, 10(1), 92-106.

Cardoso, R. E. R., \& Guzman, S. J. M. (2011). Guia de turismo: qualificação, legalização e penalização das infrações e irregularidade no exercício da profissão. Revista Âmbito Jurídico, 93.

Chilembwe, J. M., \& Mweiwa, V. (2014). Tour Guides: Are They Tourism Promoters and Developers? Case Study of Melawi. IMPACT: International Journal of Research in Business Management, 2(9), 29-46.

Chimenti, S., \& Tavares, A. M. (2007). Guia de Turismo: o profissional e a profissão. São Paulo: Senac São Paulo.

Cruz, R. de C. A. da. (2020). Ensaio sobre a relação entre desenvolvimento geográfico desigual e regionalização do espaço brasileiro. GEOUSP Espaço e Tempo (Online), 24(1), 27-50. https://doi.org/10.11606/issn.2179-0892.geousp.2020.155571. Acesso 10 mar. 2020.

Feray İRIGÜLER, \& GÜLER, M. E. (2016). Tourist Guiding : "Cinderella " of the Tourism Chapter 15 Tourist Guiding : "Cinderella" of the Tourism, (November).

Filho, J. (2004). Será 2004 o ano de regulamentação da profissão de turismólogo? Revista Turismo.

Holloway, J. C. (1981). The Guide Tour: A Sociological Approach. Annals of Tourism Research, 8(3), 377-402.

Julião, D., Cortês, F., Lohman, J., \& Costa, T. (2009). A influência das leis trabalhistas brasileiras na relação capital / trabalho dos guias de turismo. Revista Acadêmica Observatório de Inovação do Turismo, IV(3), 1-20.

Leme, F. B. M. (2010). Guias de turismo de Salvador: Olhares sobre a profissão e reflexões sobre o papel do guia como sujeito na cidade. Revista de Cultura e Turismo, 4(2), 19-37.

Lin, Y.-C., Lin, M.-L., \& Chen, Y.-C. (2017). How Tour Guides' Professional Competencies Influence on Service Quality of Tour Guiding and Tourist Satisfaction: An Exploratory Research. International Journal of Human Resource Studies, 7(1), 1-19. https://doi. org/10.5296/ijhrs.v7i1.10602. Acesso 10 mar. 2020.

Lopes, M. M., \& Matos, A. C. De. (2015). 0 que visitar em paris durante a exposição universal de 1878: um guia turístico para geólogos. Revista Iberoamericana de Turismo, 48-62.

Louzeiro, F. O. da S. (2019). Experimentando o conhecimento: o Turismo Pedagógico como ferramenta para o Ensino Profissional. Revista Brasileira de Ecoturismo (RBEcotur), 12(1), 55-66. https://doi.org/10.34024/rbecotur.2019.v12.6582. Acesso 10 mar. 2020.

Mak, A. H. N., Wong, K. K. F., \& Chang, R. C. Y. (2011). Critical issues affecting the service quality and professionalism of the tour guides in Hong Kong and Macau. Tourism Management, 32(6), 1442-1452. https://doi.org/10.1016/j.tourman.2011.01.003. Acesso 10 mar. 2020. 
Mariani, M. A. P., Arruda, D. D. O., \& Malta, M. C. M. (2015). Dinâmicas do processo de governança e coordenação dos agentes que compõem um destino de turismo sustentável, no Centro-Oeste brasileiro. Revista Brasileira de Ecoturismo, 8(2), 307-332.

Medeiros, J. L. De, Nascimento, M. A. L. do, \& Perinotto, A. R. C. (2017). Práticas turísticas por meio da análise da dimensão ambiental em geossítios do Projeto Geoparque Seridó (RN). Revista Brasileira de Ecoturismo, 10(3), 552-578.

Meira, C. M. De, Kushano, E. S., \& Hintze, H. C. (2018). Apontamentos históricos sobre a profissão do guia de turismo. Revista de Turismo Contemporâneo, 6(1), 1-19.

Nascimento, A., Silva, L. F. da, \& Grechi, D. C. (2014). A atuação do guia de turismo em Mato Grosso do Sul : diagnóstico, aspectos conceituais e perspectivas para o segmento. Revista Hospitalidade, XI(1), 23-44.

Nascimento, M. A. L. do, Gomes, C. S. C. D., \& Brito, A. dos S. S. de. (2015). Geoparque como forma de gestão territorial interdisciplinar apoiada no geoturismo: o caso do Projeto Geoparque Seridó. Revista Brasileira de Ecoturismo, 8(2), 347-364.

Neves, C. R. F., \& Costa, V. C. da. (2019). Avaliação Preliminar de Risco (APR) em atividades ecoturísticas na trilha do Pico da Tijuca, Parque Nacional da Tijuca (RJ). Revista Brasileira de Ecoturismo (RBEcotur), 12(5), 685-701. https://doi.org/10.34024/ rbecotur.2019.v12.9405. Acesso 10 mar. 2020.

Oliveira, M. D. de, \& Silva, L. F. da. (2014). Estratégias Para O Fortalecimento Do Geoturismo No Atrativo Turístico Gruta Do Lago Azul, Bonito (Ms). Revista Turismo - Visão e Ação, 16(3), 629-655. https://doi.org/10.14210/rtva.v16n3.p629. Acesso 10 mar. 2020.

Pazini, R., Braga, D. C., \& Gândara, J. M. G. (2017). A importância do guia de turismo na experiência turística: da teoria à prática das agências de receptivo de Curitiba-PR. Caderno Virtual de Turismo, 17(2), 162-182.

Pazini, R., \& Gândara, J. M. G. (2016). Os Produtos Turísticos de Curitiba, PR, Brasil na Perspectiva de Gestores de Agências de Turismo Receptivo. Revista Turismo em Análise, 27(3), 568-595. https://doi.org/10.11606/issn.1984-4867.v27i3p568-595. Acesso 10 mar. 2020.

Picazo, C. (1996). Asistencia y guía a grupos turísticos. Madrid: Editorial Síntesis.

Rabelo, M. T. O., Arts, K. A. J., Girard, P., Ioris, A. A. R., \& Figueiredo, D. M. de. (2017). Percepção dos atores sociais do turismo sobre o pulso de inundação do Pantanal (Mt). Revista Brasileira de Ecoturismo, 10(3), 708-736.

Rabotic, B. (2010). PROFESSIONAL TOURIST GUIDING : THE IMPORTANCE OF INTERPRETATION FOR TOURIST EXPERIENCES. In 20th Biennial International Congress: New Trends in Tourism and Hotel Management.

Santos, G. E. de O., Vassallo, M. D., \& Rabahy, W. A. (2009). Determinantes do valor percebido e da intenção de retorno no turismo receptor brasileiro. Revista Brasileira de Pesquisa em Turismo, 3(3), 34-56. https://doi.org/10.7784/rbtur.v3i3.206. Acesso 10 mar. 2020.

Soares, M. H. A., Ardigó, C. M., \& Melo Filho, M. E. S. de. (2017). Análise da Qualidade do Serviço: um estudo entre a percepção do cliente e do guia em roteiros regionais do SESC - Santa Catarina, Brasil. Revista Turismo em Análise, 28(3), 492-512.

Trigo, L. G. G. (2009). Turismo Básico. ( $8^{\circ}$ ed). São Paulo: Senac São Paulo.

Valle, I. A. De. (2004). A profissão de guia de turismo: conhecendo o passado e o presente para projetar o futuro. Universidade Estadual de Santa Cruz e Universidade Federal da Bahia.

Veal, A. J. (2011). Metodologia de Pesquisa em Lazer e Turismo. São Paulo: Aleph. 
Zettermann, G. D., \& Vergara, L. G. L. (2017). 0 guia de turismo: uma abordagem legal sobre uma profissão no brasil. Revista Turismo - Visão e Ação, 19(1), 185-215.

Recebido em: 10/12/2019

Aprovado em: 25/03/2020

\section{CONTRIBUIÇÕES}

Bianca Paes Garcia dos Santos: Definição do problema de pesquisa e objetivos, desenvolvimento da proposição teórica, realização da revisão bibliográfica e fundamentação teórica, escolha dos procedimentos metodológicos, coleta e análise de dados, elaboração de tabelas, gráficos e figuras, revisão crítica, redação e adequação do manuscrito às normas da RTA.

Edegar Luis Tomazzoni: Definição do problema de pesquisa e objetivos, desenvolvimento da proposição teórica, escolha dos procedimentos metodológicos, análise de dados, revisão crítica, redação e adequação do manuscrito às normas da RTA. 